\title{
Optimization of Superplastic Forming Process of AA7075 Alloy for the Best Wall Thickness Distribution
}

\author{
Manh Tien Nguyen ${ }^{1, *}$, Truong An Nguyen ${ }^{1}$, Duc Hoan Tran ${ }^{1}$, Van Thao Le ${ }^{2}$ \\ ${ }^{1}$ Faculty of Mechanical Engineering, Le Quy Don Technical University, Ha Noi, Viet Nam \\ ${ }^{2}$ Advanced Technology Center, Le Quy Don Technical University, Ha Noi, Viet Nam \\ Received 02 June 2021; received in revised form 27 July 2021; accepted 28 July 2021 \\ DOI: https://doi.org/10.46604/aiti.2021.7835
}

\begin{abstract}
This work aims to optimize the process parameters for improving the wall thickness distribution of the sheet superplastic forming process of AA7075 alloy. The considered factors include forming pressure $p$ (MPa), deformation temperature $T\left({ }^{\circ} \mathrm{C}\right.$ ), and forming time $t$ (minutes), while the responses are the thinning degree of the wall thickness $\varepsilon(\%)$ and the relative height of the product $h^{*}$. First, a series of experiments are conducted in conjunction with response surface method (RSM) to render the relationship between inputs and outputs. Subsequently, an analysis of variance (ANOVA) is conducted to verify the response significance and parameter effects. Finally, a numerical optimization algorithm is used to determine the best forming conditions. The results indicate that the thinning degree of $13.121 \%$ is achieved at the forming pressure of $0.7 \mathrm{MPa}$, the deformation temperature of $500^{\circ} \mathrm{C}$, and the forming time of 31 minutes.
\end{abstract}

Keywords: superplastic forming, wall thickness distribution, optimization, response surface, AA7075 alloy

\section{Introduction}

AA7075 is an aluminum alloy with outstanding mechanical properties such as high strength, light weight, and corrosion resistance. Therefore, AA7075 alloy is widely used in the aerospace and automotive industries. This alloy has been used to replace high strength steel on most types of cars and commercial aircraft [1-2]. However, the deformability of this alloy is limited at room temperature. The elongation to fracture for tensile tests of this alloy was achieved below $10 \%$ at room temperature $\left(20^{\circ} \mathrm{C}\right)$, resulting in its limited applicability in forming processes. To improve its deformability, other forming methods have been used to expand the application of the alloy. Superplastic forming (SPF) is one of the widely used methods. SPF is conducted within a limited range of conditions such as material microstructure, strain temperature, and strain rate. When conditions of SPF are met, the material will achieve a degree of deformation many times greater than that of the normal strain condition. In uniaxial tension, the elongations in excess of $200 \%$ are usually indicative of superplasticity [3-6].

The forming process for hollow parts from a flat sheet or a pre-profile blank or a tube blank under the action of compressed air pressure is one of the SPF methods. The received product may have a shape of forming tools [7-9]. This process can bring some attractive advantages, including large deformation ability, complex products, and a simple or no forming tools required. Moreover, the SPF technology has a great advantage in the production of single or small series of complex parts from high strength materials. However, this technology also has serious disadvantages that are an uneven distribution of wall thickness after the deformation process greatly affects the quality and working ability of the product [10-11].

* Corresponding author. E-mail address: nguyenmanhtiengcalmta@gmail.com 
The SPF by compressed air pressure depends on many parameters such as forming pressure, deformation temperature, forming time, tool size, coefficient of friction, back pressure, etc. [12-15]. The degree of influence of each parameter on the deformation ability is significantly different. The wall thickness distribution of the product is the prioritized criterion in terms of the formed part quality. Several studies on improving the distribution of the wall thickness have been carried out.

Shojaeefard et al. [16] have studied the effect of the die entry radius and the interfacial friction coefficient on the required forming time and thickness distribution of the product. Their results have shown that with lower friction coefficients, the sensitivity of the formed part thinning factor to the die entry radius variations is high. It was also concluded that a larger die entry radius along with a lower friction coefficient leads to a shorter forming time and a more uniform final part thickness distribution. Jarrar [17] found that for free-bulge forming process of AA5083 at $500^{\circ} \mathrm{C}$, single-, two-, and three-step isobaric forming process produce the same part thickness uniformity within shorter forming time compared to the forming process at a constant maximum strain rate. Kumaresan et al. [18] performed the finite element simulation using ABAQUS software to evaluate the deviation of the thickness distribution between the simulation and experiment. The process parameters selected for simulation include pressure, forming time, and initial sheet thickness. Also, Balasubramanian et al. [19] experimentally and numerically studied the three-stage forming process. Discontinuities in the thickness of the formed profile have been observed due to the transition of radius from one stage to the next. Results of this study have revealed that an optimum pressure of 0.5 MPa for achieving uniform thickness in the profile exists. Alirezaiee et al. [10] proposed a new method to produce a part with a fairly uniform thickness distribution. In their proposed method, a die having a movable segment is used. By moving this segment during the process, the part is formed during two stages and final thickness distribution is controlled.

One of the factors affecting the forming process, which has also been mentioned in many studies, is the change in the microstructure of the material during the SPF process. Since the grain size is a preliminary criterion for obtaining superplasticity in any material, its stability at the deformation temperature plays a significant role. The deformation ability of the material will be significantly reduced as the average grain size increases during the SPF process [20-21]. Moreover, abnormal grain growth is also a major metallurgical aspect in superplastic deformation [22-23].

However, the aforementioned publications indicated that the process parameter optimizations for sheet SPF processes about the formed part quality have not been thoroughly investigated. Recently, many technological solutions have been researched to improve the thinning degree of the wall thickness and increase the product quality. The new SPF process was developed based on the back pressure principle. Besides hardware developments, forming parameter optimization is still an effective approach in terms of costs and time. The AA7075 high-strength aluminum alloy was selected as the workpiece material due to its wide industrial applications.

This work aims to optimize the process parameters for improving the wall thickness distribution of the sheet SPF process of AA7075 alloy. The considered factors include forming pressure $p(\mathrm{MPa})$, deformation temperature $T\left({ }^{\circ} \mathrm{C}\right)$, and forming time $t$ (minutes), while the responses are the thinning degree of the wall thickness $\varepsilon(\%)$ and the relative height of the product $h *$. First, a series of experiments are conducted in conjunction with the response surface method (RSM) to render the relationship between inputs and outputs. Subsequently, an analysis of variance (ANOVA) is conducted to verify the response significance and parameter effects. Finally, a numerical optimization algorithm is used to determine the best forming conditions.

\section{Research Methodology}

\subsection{Optimization problem}

The thinning degree of the wall thickness $\varepsilon(\%)$ is one of the important criteria with regard to the quality of SPF products. The goal of the current work is to optimize the process parameters, including forming pressure, deformation temperature, and forming time for minimizing the thinning degree. The schematic diagram of the sheet SPF process under the action of 
compressed air pressure is depicted in Fig. 1. The die is fastened by bolts, and the pneumatic tube into the die is welded with a sealing cap. The 45 steel is selected as the die material due to the medium forming temperature. The die and the stroke sensor are placed in the furnace during deformations.

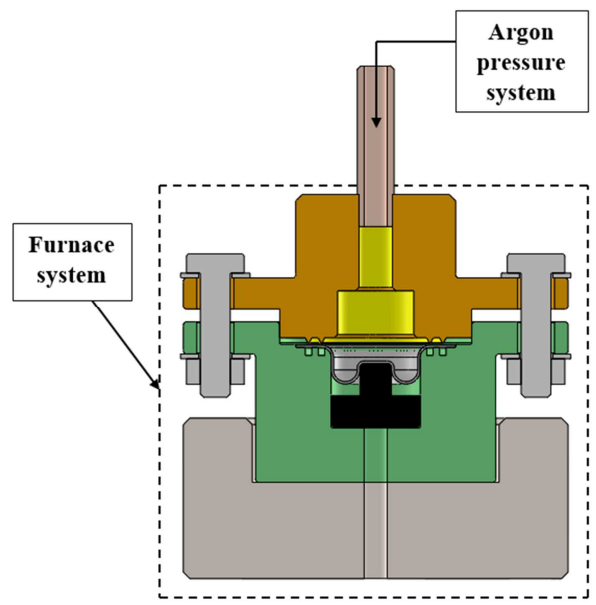

Fig. 1 Schematic diagram of the sheet SPF process

As shown in Table 1, the limits of variables are denoted as $-1,0$, and +1 for the lower value, middle value, and higher value, and the input variables are denoted as $A$ for forming pressure (MPa), $B$ for deformation temperature $\left({ }^{\circ} \mathrm{C}\right)$, and $C$ for forming time (min). The parameter ranges are determined based on the references [7, 11, 24]. Consequently, the optimizing issue is to find the minimum thinning degree based on the optimization process parameters [25].

Table 1 Levels and their values of the process parameters

\begin{tabular}{|c|c|c|c|c|}
\hline Symbol & Parameters & Level -1 & Level 0 & Level +1 \\
\hline$p$ & $A$ : forming pressure $(\mathrm{MPa})$ & 0.7 & 0.8 & 0.9 \\
\hline$T$ & $B:$ deformation temperature $\left({ }^{\circ} \mathrm{C}\right)$ & 500 & 515 & 530 \\
\hline$t$ & $C:$ forming time $(\mathrm{min})$ & 20 & 30 & 40 \\
\hline
\end{tabular}

\subsection{Optimization framework}

In the Box-Behnken design (BBD), three levels for each design parameter or factor are required, with all design points lying on the same sphere and with at least three or five runs at the center point. BBD is applied instead of the full-factorial one to decrease the number of experiments and ensure the predicting accuracy. The predictive mathematical model of the thinning degree is then developed with respect to process parameters using RSM [26-28]. Subsequently, a fitness analysis is conducted in order to investigate the significance of the proposed model and the factor is chosen. To solve the optimization problem, an advanced technique entitled desirability function (DF) is adopted for obtaining optimal values. In addition to the design points, a set of random points are checked to see if there is a more desirable solution. The influence of the parameters on the objective function will help the technology design process. The feasible solutions could be obtained with a minimal cost, from a problem that potentially has a great number of solutions [29-30]. As a result, an integrative approach combining BBD, RSM, and DF can be considered a powerful method to find global optimal process parameters with a smaller number of experiments as well as less computational effort.

\section{Experimental Procedures}

The experimental specimens are cut from a flat sheet of the thickness of $1.2 \mathrm{~mm}$ to have a diameter of $50 \mathrm{~mm}$. The material used in this study is an AA7075 alloy. The chemical composition of the AA7075 alloy listed in Table 2 is expressed in weight percent (\%wt). The AA7075 alloy is prepared to fine stable grain size with an average grain size of about $13 \mu \mathrm{m}$. The experimental tests are carried out under SPF conditions. The experimental equipment system is shown in Fig. 2. 
Table 2 Chemical composition of the analyzed AA7075 alloy

\begin{tabular}{|c|c|c|c|c|c|c|c|c|c|}
\hline $\mathrm{Zn}$ & $\mathrm{Mg}$ & $\mathrm{Cu}$ & $\mathrm{Fe}$ & $\mathrm{Cr}$ & $\mathrm{Ti}$ & $\mathrm{Zr}$ & $\mathrm{Mn}$ & $\mathrm{Si}$ & $\mathrm{Al}$ \\
\hline 5.35 & 2.34 & 1.32 & 0.30 & 0.22 & 0.04 & 0.0027 & 0.024 & 0.05 & Balance \\
\hline
\end{tabular}

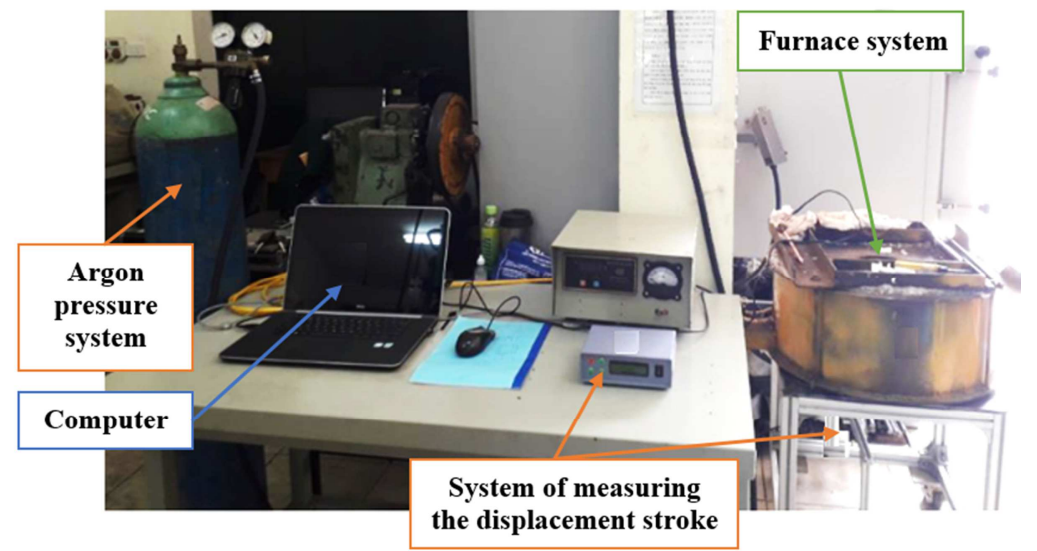

Fig. 2 The experimental equipment system

The deformed specimens are exhibited in Fig. 3. The position of wall thickness measurement is determined as shown in Fig. 4. At that position, the thinning degree is the greatest. The wall thickness values are measured by a JENA universal microscope. The overall height of the product is determined and shown in Fig. 5. The average response values are observed repeatedly three times. The experimental data of the thinning degree of the wall thickness $\varepsilon$ and the relative height of the product $h^{*}$ are exhibited in Table 2. The thinning degree of the wall thickness is the ratio between the amount of thinning at a dangerous position and the thickness calculated according to the law of constant volume. The relative height of the product is the ratio between the overall height $H_{i}$ and outside diameter $D_{p}$ of the part.

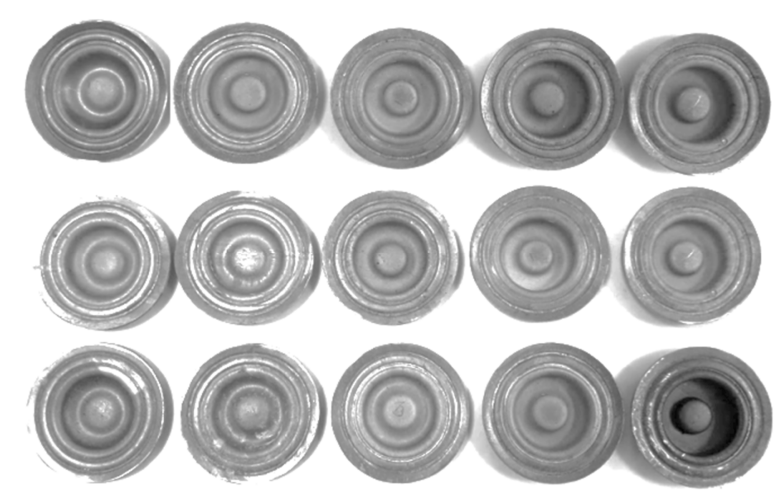

Fig. 3 The specimens after SPF processes

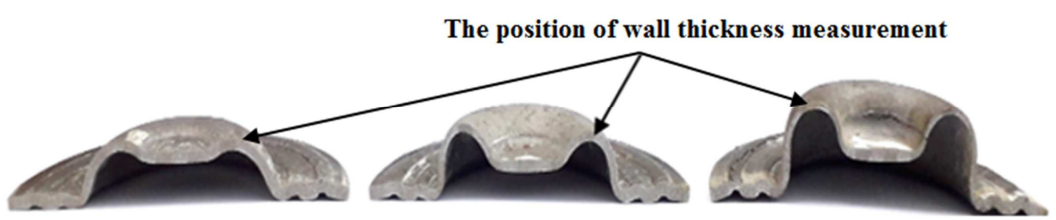

Fig. 4 The position of wall thickness measurement of deformed specimens

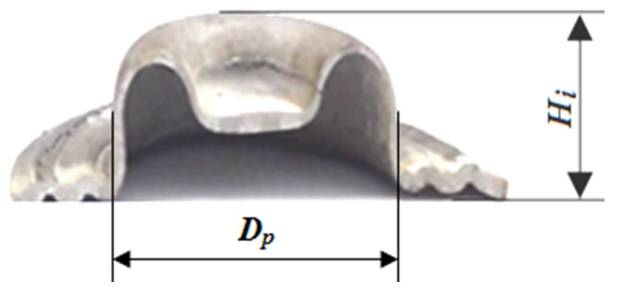

Fig. 5 Determination of the overall height $H_{i}$ and outside diameter $D_{p}$ of the product 


\section{Results and Discussion}

\subsection{Model fitness investigation}

In this study, ANOVA is used to determine the adequacy and significance of models. In addition, it is used to evaluate the effect of lack-of-fit on the models and the significance of the individual model coefficient. There are 15 test trials performed based on the design of the experiment method as shown in Table 3. ANOVA results of the thinning degree and relative height are shown in Table 4 and Table 5. The significant coefficients are selected based on the $p$-values of the parameters considered. The parameters are modeled using a confidence level of $95 \%$. Hence, the factors with $p$-values less than 0.05 are considered significant.

Table 3 Experimental results

\begin{tabular}{|c|c|c|c|c|c|}
\hline \multirow{2}{*}{$\begin{array}{l}\text { Number of } \\
\text { experiments }\end{array}$} & \multirow{2}{*}{$\begin{array}{c}\text { Factor } 1 \\
A \text { : forming } \\
\text { pressure }(\mathrm{MPa})\end{array}$} & \multirow{2}{*}{$\begin{array}{c}\text { Factor } 2 \\
B: \text { deformation } \\
\text { temperature }\left({ }^{\circ} \mathrm{C}\right)\end{array}$} & \multirow{2}{*}{$\begin{array}{c}\text { Factor } 3 \\
C: \text { forming time } \\
\quad(\min )\end{array}$} & \multicolumn{2}{|c|}{ Responses } \\
\hline & & & & $\begin{array}{l}R 1: \text { thinning degree } \\
\varepsilon(\%)\end{array}$ & $\begin{array}{l}R 2 \text { : relative height } \\
\text { of the product } h^{*}\end{array}$ \\
\hline 1 & -1 & -1 & 0 & 13 & 0.25 \\
\hline 2 & +1 & -1 & 0 & 15 & 0.32 \\
\hline 3 & -1 & +1 & 0 & 16.8 & 0.30 \\
\hline 4 & +1 & +1 & 0 & 16.5 & 0.37 \\
\hline 5 & -1 & 0 & -1 & 16.5 & 0.34 \\
\hline 6 & +1 & 0 & -1 & 17.8 & 0.27 \\
\hline 7 & -1 & 0 & +1 & 17 & 0.40 \\
\hline 8 & +1 & 0 & +1 & 18 & 0.49 \\
\hline 9 & 0 & -1 & -1 & 17.8 & 0.30 \\
\hline 10 & 0 & +1 & -1 & 18.4 & 0.42 \\
\hline 11 & 0 & -1 & +1 & 17 & 0.33 \\
\hline 12 & 0 & +1 & +1 & 20 & 0.45 \\
\hline 13 & 0 & 0 & 0 & 17.4 & 0.48 \\
\hline 14 & 0 & 0 & 0 & 17.2 & 0.48 \\
\hline 15 & 0 & 0 & 0 & 17 & 0.44 \\
\hline
\end{tabular}

Table 4 ANOVA result for thinning degree model

\begin{tabular}{|c|c|c|c|c|c|c|}
\hline Source & Sum of squares & Degree of freedom & Mean square & $F$-value & $p$-value & Significance \\
\hline Model & 33.48 & 9 & 3.72 & 38.16 & 0.0004 & Significant \\
\hline$A-A$ & 2.00 & 1 & 2.00 & 20.51 & 0.0062 & - \\
\hline$B-B$ & 9.90 & 1 & 9.90 & 101.55 & 0.0002 & - \\
\hline$C-C$ & 0.2813 & 1 & 0.2813 & 2.88 & 0.1502 & - \\
\hline$A B$ & 1.32 & 1 & 1.32 & 13.56 & 0.0142 & - \\
\hline$A C$ & 0.0225 & 1 & 0.0225 & 0.2308 & 0.6512 & - \\
\hline$B C$ & 1.44 & 1 & 1.44 & 14.77 & 0.0121 & - \\
\hline$A^{2}$ & 7.50 & 1 & 7.50 & 76.90 & 0.0003 & - \\
\hline$B^{2}$ & 0.7477 & 1 & 0.7477 & 7.67 & 0.0394 & - \\
\hline$C^{2}$ & 8.87 & 1 & 8.87 & 90.98 & 0.0002 & - \\
\hline Residual & 0.4875 & 5 & 0.0975 & - & - & - \\
\hline Lack-of-fit & 0.4075 & 3 & 0.1358 & 3.40 & 0.2358 & Not significant \\
\hline Pure error & 0.0800 & 2 & 0.0400 & - & - & - \\
\hline Corrected total & 33.97 & 14 & - & - & - & - \\
\hline $\boldsymbol{R}^{\mathbf{2}}$ & 0.9856 & - & - & - & - & - \\
\hline Adjusted $\boldsymbol{R}^{\mathbf{2}}$ & 0.9598 & - & - & - & - & - \\
\hline Predicted $\boldsymbol{R}^{\mathbf{2}}$ & 0.8028 & - & - & - & - & - \\
\hline Adequate precision & 27.7014 & - & - & - & - & - \\
\hline
\end{tabular}


As shown in Table 4 and Table 5, the $F$-values 38.16 and 25.93 indicate the significance of the quadratic models. In these models, all the single terms $(p, T$, and $t)$ and quadratic terms $\left(p^{2}, T^{2}\right.$, and $\left.t^{2}\right)$ are found to be significant model terms. The insignificant terms ( $p T, p t$, and $T t$ ) should be eliminated in the design space in order to save computational time. Additionally, the $R^{2}$-value of the thinning degree is 0.9856 , indicating that $98.56 \%$ of the total variations are explained by the model. The $R^{2}$-value of the relative height is 0.9790 , indicating that $97.9 \%$ of the total variations are explained by the model. Moreover, the comparison results from the adjusted $R^{2}$-value and predicted $R^{2}$-value using ANOVA indicate that the quadratic model is more accurate than the linear one. Adequate precision is used to measure the signal to noise ratio. The ratio greater than 4 is desirable. In the thinning degree model and the relative height model, the adequate precisions are 27.7014 and 15.1235 respectively, indicating adequate signals. These models can be used to navigate the design space. The lack-of-fit is not significant relative to the pure error. Non-significant lack-of-fit is good.

Table 5 ANOVA result for relative height model

\begin{tabular}{|c|c|c|c|c|c|c|}
\hline Source & Sum of squares & Degree of freedom & Mean square & $F$-value & $p$-value & Significance \\
\hline Model & 0.0836 & 9 & 0.0093 & 25.93 & 25.93 & Significant \\
\hline$A-A$ & 0.0036 & 1 & 0.0036 & 10.08 & 10.08 & - \\
\hline$B-B$ & 0.0136 & 1 & 0.0136 & 37.99 & 37.99 & - \\
\hline$C-C$ & 0.0162 & 1 & 0.0162 & 45.21 & 45.21 & - \\
\hline$A B$ & 0.0006 & 1 & 0.0006 & 1.74 & 1.74 & - \\
\hline$A C$ & 0.0121 & 1 & 0.0121 & 33.77 & 33.77 & - \\
\hline$B C$ & 0.0009 & 1 & 0.0009 & 2.51 & 2.51 & - \\
\hline$A^{\mathbf{2}}$ & 0.0285 & 1 & 0.0285 & 79.64 & 79.64 & - \\
\hline$B^{\mathbf{2}}$ & 0.0103 & 1 & 0.0103 & 28.85 & 28.85 & - \\
\hline$C^{\mathbf{2}}$ & 0.0009 & 1 & 0.0009 & 2.45 & 2.45 & - \\
\hline Residual & 0.0018 & 5 & 0.0004 & - & - & - \\
\hline Lack-of-fit & 0.0009 & 3 & 0.0003 & 0.7115 & 0.7115 & Not significant \\
\hline Pure error & 0.0009 & 2 & 0.0004 & - & - & - \\
\hline Corrected total & 0.0854 & 14 & - & - & - & - \\
\hline $\boldsymbol{R}^{\mathbf{2}}$ & 0.9790 & - & - & - & - & - \\
\hline Adjusted $\boldsymbol{R}^{\mathbf{2}}$ & 0.9413 & - & - & - & - & - \\
\hline Predicted $\boldsymbol{R}^{\mathbf{2}}$ & 0.8039 & - & - & - & - & - \\
\hline Adequate precision & 15.1235 & - & - & - & - & - \\
\hline
\end{tabular}

\subsection{Model for thinning degree and relative height}

The models of thinning degree and relative height are developed in terms of input parameters using RSM. From the experimental values, the coefficients of the regression equations are calculated. The regression coefficients of insignificant terms are eliminated based on ANOVA results. Consequently, the regression response surface models showing the thinning degree of the wall thickness $\varepsilon$ and the relative height $h^{*}$ are expressed by Eq. (1) and Eq. (2) which show the final equation in terms of coded factors.

$$
\begin{aligned}
\mathcal{E}= & 17.2+0.5 \times A+1.1125 \times B+0.1875 \times C-0.575 \times A \times B-0.075 \times A \times C+0.6 \times B \times C \\
& -1.425 \times A^{2}-0.45 \times B^{2}+1.55 \times C^{2} \\
h^{*}= & 0.4633+0.02112 \times A+0.0412 \times B+0.045 \times C-0.0125 \times A \times B+0.55 \times A \times C-0.015 \times B \times C \\
& -0.0879 \times A^{2}-0.0529 \times B^{2}-0.0154 \times C^{2}
\end{aligned}
$$

Fig. 6(a) and Fig. 6(b) represent the normal probability curves for thinning degree and relative height respectively to check the adequacy of models. As all points are in a straight line, it can be concluded that the models are adequate [29-30]. 


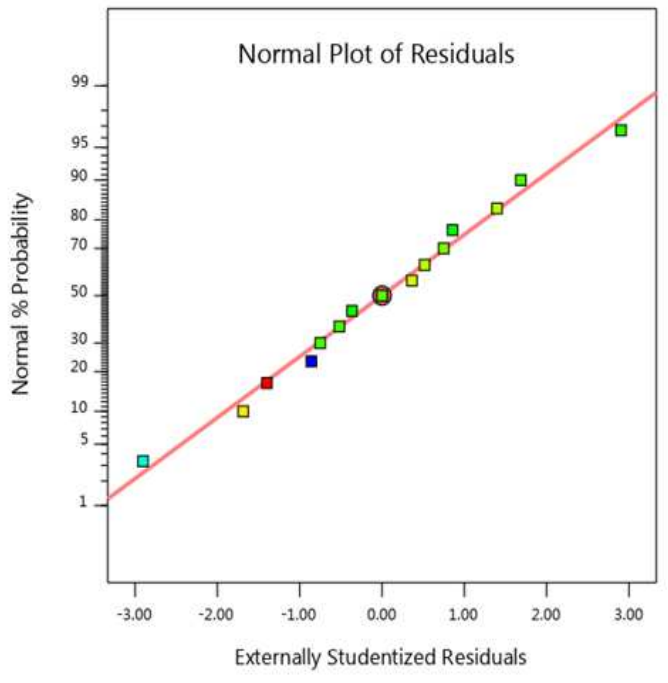

(a) Thinning degree

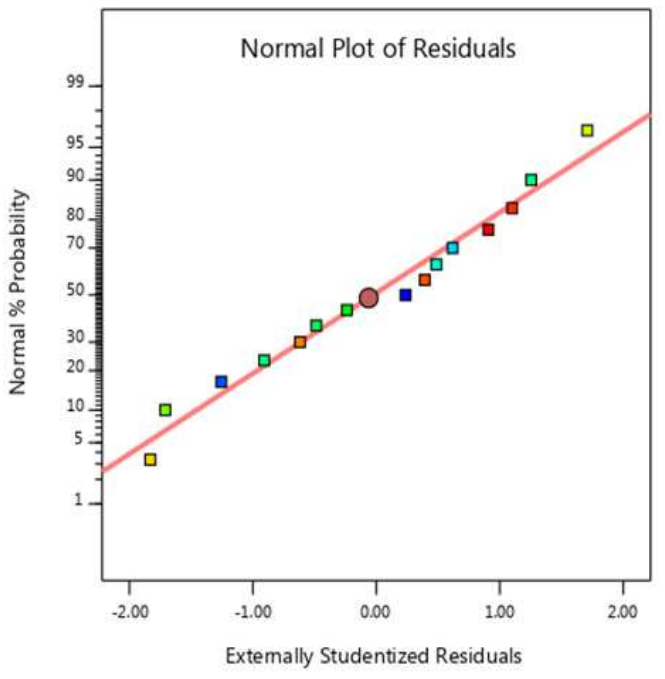

(b) Relative height

Fig. 6 Residual plots for the developed models

\subsection{Factor effect analysis}

\subsubsection{Effect of process parameters on thinning degree $\varepsilon$}

The effects of process parameters on the objective are investigated using the contour plots (2D and 3D) which are considered in full parameter ranges, at each level of the focal position. Fig. 7 shows that an increase of the forming time results in a decreased thinning degree, until the optimum value of around $30 \mathrm{~min}$. The thinning degree is then increased with the continuous increase of the forming time. Besides, when the strain temperature increases from $500^{\circ} \mathrm{C}$ to $530^{\circ} \mathrm{C}$, the degree of thinning increases. This phenomenon can be explained as follows. When the forming time and deformation temperature increase, the grain grows faster. Therefore, it reduces the deformation rate and deformation degree of the specimens. The degree of thickness distribution becomes uneven, the thinning degree at the dangerous position will increase $[7,11,24]$.

As shown in Fig. 7, when the forming pressure increases, the thinning degree increases. However, when the pressure increases beyond $0.8 \mathrm{MPa}$, the thinning degree of the wall thickness at the dangerous position decreases. This phenomenon can be explained as follows. When the strain rate is high, the time is not enough for the corresponding diffusion process to create the planes favorable for sliding, so the stress increases and the deformation degree of the specimen decreases [24].

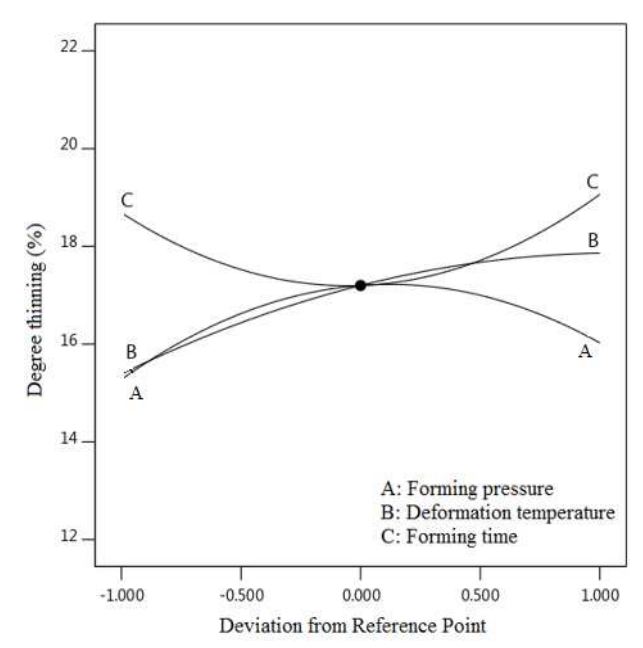

(a) 2D perturbation plot of process parameters

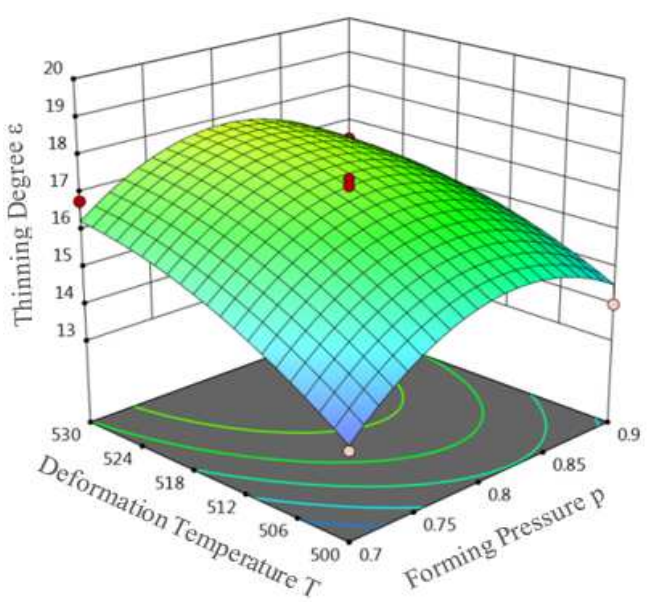

(b) $3 \mathrm{D}$ interaction plots of forming pressure and deformation temperature

Fig. 7 Effect of processing parameters on the thinning degree 


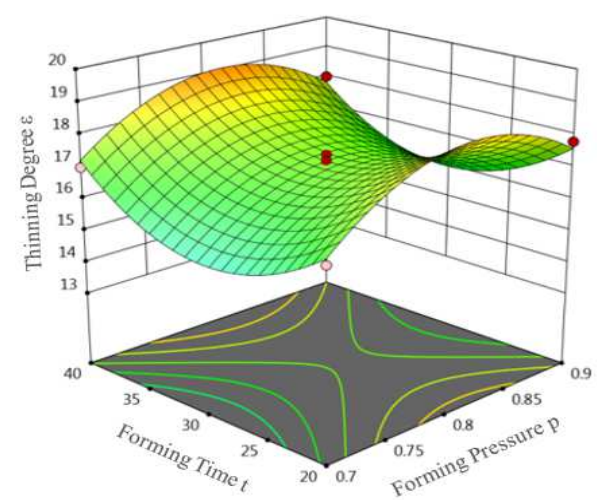

(c) 3D interaction plots of forming pressure and forming time

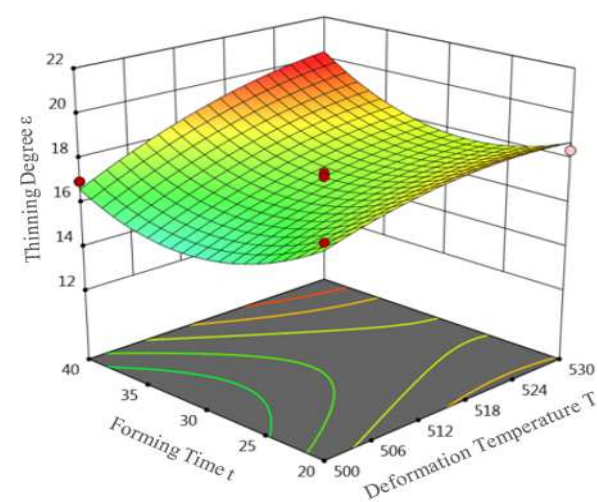

(d) 3D interaction plots of forming time and deformation temperature

Fig. 7 Effect of processing parameters on the thinning degree (continued)

\subsubsection{Effect of process parameters on the relative height of product $h^{*}$}

In Fig. 8, it is shown that the influence of process parameters including forming pressure, deformation temperature, and forming time leads to the relative height of the product. As the forming pressure and deformation temperature increase, the relative height increases. However, when the forming pressure and strain temperature increase to a certain value, the relative height of the product tends to decrease. Because of this, the higher strain rate and high temperature will make the grain microstructure of the material grow, reducing the possibility of deformation [24]. The forming time increases (from 20 to 40 $\mathrm{min}$ ), and the relative height of the product increases accordingly. Besides, with a long forming time, the thinning degree of the wall thickness increases. This may result in product destruction.

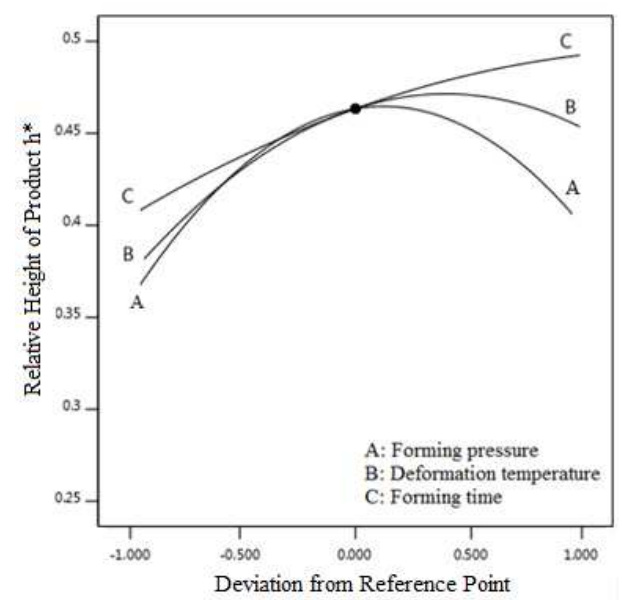

(a) $2 \mathrm{D}$ perturbation plot of process parameters

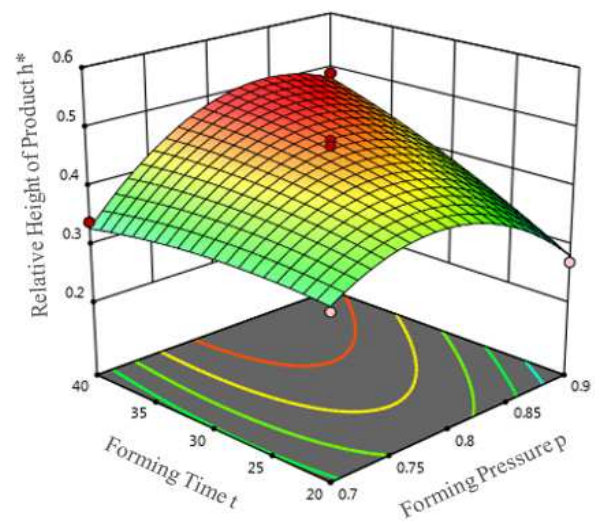

(c) 3D interaction plots of forming pressure and forming time

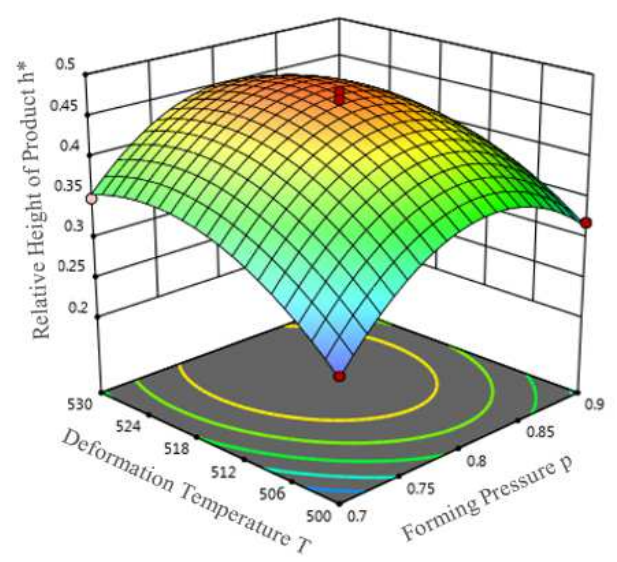

(b) $3 \mathrm{D}$ interaction plots of forming pressure and deformation temperature

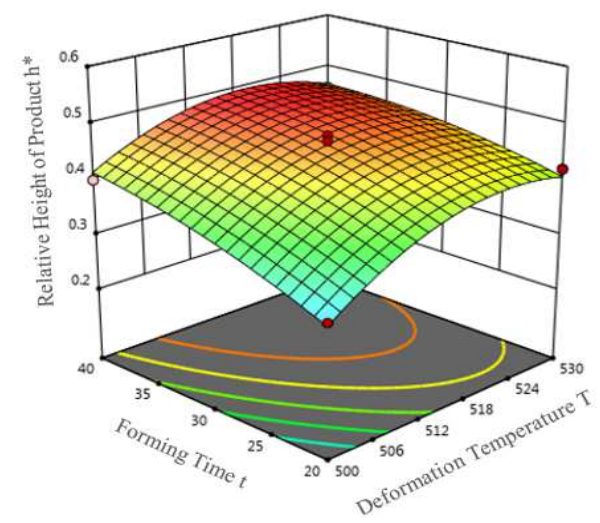

(d) 3D interaction plots of forming time and deformation temperature

Fig. 8 Effect of processing parameters on the relative height of the product 


\section{Optimization Results}

After building the statistical regression equation showing the relationship between process parameters and process response, the equation is used to solve the optimization problem. According to the discussion above, it can be concluded that the process parameters of forming pressure, deformation temperature, and forming time have significant and complex effects on the thinning degree of the wall thickness model. The optimization issue can be solved using RSM. Table 6 shows that the thinning degree of the wall thickness $\varepsilon$ of $13,121 \%$ is observed at $p=0.7 \mathrm{MPa}, T=500^{\circ} \mathrm{C}$, and $t=31 \mathrm{~min}$, respectively.

Table 6 Optimization results using RSM

\begin{tabular}{|c|c|c|c|c|c|c|}
\hline \multicolumn{7}{|c|}{ Constraints } \\
\hline Name & Goal & Lower limit & Upper limit & Lower weight & Upper weight & Importance \\
\hline$A: A$ & In range & 0.7 & 0.9 & 1 & 1 & 3 \\
\hline$B: B$ & In range & 500 & 530 & 1 & 1 & 3 \\
\hline$C: C$ & In range & 20 & 40 & 1 & 1 & 3 \\
\hline$R 1$ & Minimize & 13 & 20 & 1 & 1 & 3 \\
\hline \multicolumn{7}{|c|}{ Solutions } \\
\hline Number & $A$ & $B$ & $C$ & $R 1$ & Desirability & Selection \\
\hline $\mathbf{1}$ & $\mathbf{0 . 7 0 0}$ & $\mathbf{5 0 0 . 0 0 0}$ & $\mathbf{3 1 . 0 0 6}$ & $\mathbf{1 3 . 1 2 1}$ & $\mathbf{0 . 9 8 3}$ & Selected \\
\hline 2 & 0.700 & 500.000 & 31.123 & 13.121 & 0.983 & - \\
\hline 3 & 0.700 & 500.013 & 30.671 & 13.125 & 0.982 & - \\
\hline 4 & 0.700 & 500.000 & 30.806 & 13.126 & 0.982 & - \\
\hline 5 & 0.700 & 500.000 & 31.616 & 13.127 & 0.982 & - \\
\hline
\end{tabular}

\section{Conclusions}

In this study, an integrative approach using the physical experiment, RSM model, and the DF algorithm was used to optimize the process parameters concerning the thinning degree of the wall thickness. The relationship between process parameters and the thinning degree was constructed through RSM and experimental data. DF was applied to determine the optimal design variables and the response. The main conclusions from the research results of the current work can be drawn as follows:

(1) The thinning degree is decreased with a higher value of the forming time until it reaches the optimal points. With increased factors, the thinning degree increases. Additionally, an increased forming pressure or deformation temperature results in a higher thinning degree value.

(2) The mathematical model of the thinning degree developed using BBD and RSM predicts the response values with sufficient accuracy.

(3) In the range of studied parameters, the thinning degree of $13,121 \%$ is achieved at $p=0.7 \mathrm{MPa}, T=500^{\circ} \mathrm{C}$, and $t=31 \mathrm{~min}$.

(4) The research results allow determining the relative height of the product $h^{*}$ corresponding to the thinning degree of the wall thickness $\varepsilon$ in the range of allowable limit values.

\section{Conflicts of Interest}

The authors declare no conflict of interest.

\section{References}

[1] N. E. Prasad, A. A. Gokhale, and R. J. H. Wanhill, Aluminum-Lithium Alloys: Processing, Properties, and Applications, Oxford: Elsevier, 2014.

[2] E. A. Starke and J. T. Staley, "Application of Modern Aluminum Alloys to Aircraft," Progress in Aerospace Sciences, vol. 32, no. 2-3, pp. 131-172, 1996. 
[3] R. J. Bhatt, “Advanced Approaches in Superplastic Forming-A Case Study,” Journal of Basic and Applied Engineering Research, vol. 1, pp. 57- 64, October 2014.

[4] I. Charit, R. S. Mishra, and M. W. Mahoney, "Multi-Sheet Structures in 7475 Aluminum by Friction Stir Welding in Concert with Post-Weld Superplastic Forming," Scripta Materialia, vol. 47, no. 9, pp. 631-636, November 2002.

[5] S. X. McFadden, R. S. Mishra, R. Z. Valiev, A. P. Zhilyaev, and A. K. Mukherjee, "Low-Temperature Superplasticity in Nanostructured Nickel and Metal Alloys," Nature, vol. 398, no. 6729, pp. 684-686, April 1999.

[6] Y. Wang and R. S. Mishra, "Finite Element Simulation of Selective Superplastic Forming of Friction Stir Processed 7075 Al Alloy," Materials Science and Engineering: A, vol. 463, no. 1-2, pp. 245-248, August 2007.

[7] G. Giuliano, Superplastic Forming of Advanced Metallic Materials: Methods and Applications, Cambridge: Woodhead, 2011.

[8] C. H. Hamilton and N. E. Paton, Superplasticity and Superplastic Forming: Proceedings of an International Conference on Superplasticity and Superplastic Forming, Warrendale: The Minerals, Metals, and Materials Society,1989.

[9] C. K. Syn, M. J. O’Brien, D. R. Lesuer, and O. D. Sherby, “An Analysis of Gas Pressure Forming of Superplastic Al 5083 Alloy," International Conference on Light Materials for Transportation Systems, May 2001, pp. 1-8.

[10] M. Alirezaiee, R. J. Nedoushan, and D. Banabic, "Improvement of Product Thickness Distribution in Gas Pressure Forming of a Hemispherical Part," Proceedings of the Romanian Academy, vol. 17, no. 3, pp. 245-252, July-September 2016.

[11] T. G. Nieh, J. Wadsworh, and O. D. Sherby, Superplasticity in Metals and Ceramics, Cambridge: Cambridge University Press, 2005.

[12] A. O. Caballero, O. A. Ruano, E. F. Rauch, and F. Carreño, "Severe Friction Stir Processing of an Al-Zn-Mg-Cu Alloy: Misorientation and Its Influence on Superplasticity," Materials and Design, vol. 137, pp. 128-139, October 2017.

[13] J. R. Groza, J. F. Shackelford, M. T. Lavernia, and M. T. Powers, Materials Processing Handbook, Boca Raton: CRC Press, 2007.

[14] A. D. Jose and J. Babu, "Experimental Studies on Thinning Characteristics of Superplastic Hemi-Spherical Forming," International Journal of Emerging Technology and Advanced Engineering, vol. 5, no. 1, pp. 104-109, January 2015.

[15] A. Smolej, B. Skaza, and M. Fazarinc, "Determination of the Strain-Rate Sensitivity and the Activation Energy of Deformation in the Superplastic Aluminum Alloy Al-Mg-Mn-Sc," Materials and Geoenvironment, vol. 56, no. 4, pp. 389-399, December 2009.

[16] M. H. Shojaeefard, A. Khalkhali, and E. Miandoabchi, "Effects of Process Parameters on Superplastic Forming of a License Plate Pocket Panel," Advanced Design and Manufacturing Technology, vol. 7, no. 2, pp. 25-33, June 2014.

[17] F. Jarrar, "Designing Gas Pressure Profiles for AA5083 Superplastic Forming," Procedia Engineering, vol. 81, pp. 1084-1089, October 2014.

[18] G. Kumaresan and A. Jothilingam, "Experimental and FE Simulation Validation of Sheet Thickness Optimization in Superplastic Forming of Al Alloy,” Journal of Mechanical Science and Technology, vol. 30, no. 7, pp. 3295-3300, September 2016.

[19] M. Balasubramanian, P. Ganesh, K. Ramanathan, and V. S. S. Kumar, "Superplastic Forming of a Three-Stage Hemispherical 5083 Aluminium Profile,” Journal of Mechanical Engineering, vol. 61, no. 6, pp. 365-373, Arpil 2015.

[20] D. Harwani, V. Badheka, V. Patel, and J. Andersson, "Developing Superplasticity in Magnesium Alloys with the Help of Friction Stir Processing and Its Variants-A Review,” Journal of Materials Research and Technology, vol. 12, pp. 2055-2075, May-June 2021.

[21] V. Patel, V. Badheka, W. Li, and S. Akkireddy, "Hybrid Friction Stir Processing with Active Cooling Approach to Enhance Superplastic Behavior of AA7075 Aluminum Alloy," Archives of Civil and Mechanical Engineering, vol. 19, no. 4, pp. 1368-1380, August 2019.

[22] V. Patel, W. Li, A. Vairis, and V. Badheka, "Recent Development in Friction Stir Processing as a Solid-State Grain Refinement Technique: Microstructural Evolution and Property Enhancement," Critical Reviews in Solid State and Materials Sciences, vol. 44, no. 5, pp. 378-426, July 2019.

[23] V. V. Patel, V. Badheka, and A. Kumar, "Friction Stir Processing as a Novel Technique to Achieve Superplasticity in Aluminum Alloys: Process Variables, Variants, and Applications,” Metallography, Microstructure, and Analysis, vol. 5, no. 4, pp. 278-293, August 2016.

[24] N. M. Tien, N. T. An, T. D. Hoan, L. D. Giang, and L. T. Tan, "Experimental Study on Effects of Process Parameters on Superplastic Deformation Ability of 7075 Aluminium Alloy Using Taguchi Method," International Conference on Engineering Research and Applications, December 2019, pp. 328-334.

[25] C. F. Wu and M. Hamada, Experiments: Planning, Analysis, and Optimization, Hoboken: Wiley, 2009. 
[26] S. Gopalakannan, T. Senthilvelan, and S. Ranganathan, "Modeling and Optimization of EDM Process Parameters on Machining of Al 7075-B4C MMC Using RSM,” Procedia Engineering, vol. 38, pp. 685-690, 2012.

[27] R. Kumar and S. Chauhan, "Study on Surface Roughness Measurement for Turning of Al 7075/10/SiCp and Al 7075 Hybrid Composites by Using Response Surface Methodology (RSM) and Artificial Neural Networking (ANN)," Measurement, vol. 65, pp. 166-180, April 2015.

[28] E. Salur, A. Aslan, M. Kuntoglu, A. Gunes, and O. S. Sahin, "Experimental Study and Analysis of Machinability Characteristics of Metal Matrix Composites During Drilling," Composites Part B: Engineering, vol. 166, pp. 401-413, June 2019.

[29] S. A. Sonawane and M. L. Kulkarni, "Multi-Response Optimization of Wire Electrical Discharge Machining for Titanium Grade-5 by Weighted Principal Component Analysis," International Journal of Engineering and Technology Innovation, vol. 8, no. 2, pp. 133-145, March 2018.

[30] C. S. Syan and G. Ramsoobag, "A Differential Evolution Optimization Approach for Parameters Estimation of Truncated and Censored Failure Time Data,” Advances in Technology Innovation, vol. 3, no. 4, pp. 185-194, October 2018.

Copyright $\odot$ by the authors. Licensee TAETI, Taiwan. This article is an open access article distributed under the terms and conditions of the Creative Commons Attribution (CC BY-NC) license (https://creativecommons.org/licenses/by-nc/4.0/). 